\title{
Rei de los brujos: Introducción y transcripción del documento: Proceso a Domingo Rojas, mulato, por hechicero y vago. $1765^{1}$
}

\author{
Eduardo Valenzuela Avaca $(*)$
}

\section{RESUMEN}

El caso de Domingo Rojas, mulato, hechicero, se inscribe en un conjunto de causas por heterodoxia llevadas por la Justicia Real durante el s.XVIII, mostrándonos no solo la praxis judicial que sostiene estos procesos sino el conjunto de signos y rasgos que configuran un lenguaje común a testigos, reos y jueces. El presente artículo expone la transcripción de este proceso inédito de hechicería, y arroja algunas claves de lectura en el contexto general de la fenomenología heterodoxa en Chile colonial.

\section{Palabras clave:}

$$
\text { Hechicería - brujería - heterodoxia - siglo XVIII - Talca. }
$$

\footnotetext{
ABSTRACT

The case of Domingo Rojas, mulato, hechicero, is registered in a set of criminal prosecutions for heterodoxy, followed by the Justicia Real during S.XVIII in Chile, showing not only the legal practices that support these processes but also the set of signs and elements that form a common languague for witnesses, defendants and judges. This paper presents the transcription of a new process of hechicería, and

(*) Licenciado en Historia, Pontificia Universidad Católica de Chile. Magíster (c) en Historia, Universidad de Chile.

Artículo recibido el 7 de diciembre de 2010. Aceptado por el Comité Editorial el 11 de abril de 2011.

Correo electrónico: ejvalena@uc.cl

${ }^{1}$ A.N.Ch. Fondo Archivo Judicial de Talca, Legajo 233, p. 31. Este proceso forma parte del corpus analizado por el autor en su tesis para el grado de Magíster en Historia, trabajo aun no publicado.
} 
throws some keys to understand the general context of phenomenology heterodox in colonial Chile.

Key words:

Sorcery - witchcraft - heterodoxy - XVIII Century - Talca.

El 24 de Septiembre de 1765, en la doctrina de Vichuquén, Talca, se inicia un proceso criminal contra Domingo Rojas, de cuarenta años, por las continuas quejas públicas que aseguraban que el mulato ejecutaba maleficios contra los vecinos de Talca y dominaba el arte diabólico, herramientas con las que habría causado enfermedad a distintas personas.

Un primer elemento que llama nuestra atención es la jurisdicción sobre la causa. Tanto la naturaleza de las acusaciones -heterodoxia- como los efectos de esta son de competencia del Tribunal Inquisitorial de Lima, sin embargo, el proceso es llevado por la Justicia Ordinaria, utilizando el fuero que excusaba a indígenas -tiernos en la fe-de comparecer ante tribunales tan especializados como el inquisitorial.

No es solo teoría legalista. Fray Cristóbal Núñez, dominico español, fue deportado desde Chile a Lima, en 1572 para enfrentar a los tribunales por haber pedido a un grupo de indios que le ayudaran a encontrar el ladrón que había hurtado cierto objeto, por medio "de sus hechizos" 2 es decir, lo que corresponde a una práctica heterodoxa -adivinación- varios grados menos grave que la acusación de maleficio. Quien pueda pensar que este ensañamiento se debe a su dignidad eclesiástica puede consultar el caso de María de Encío, mujer natural de Bayona en Galicia residente en Santiago de Chile, a quien se le secuestraron sus bienes porque "miraba las rayas de las manos, y creía en sueños y otras supersticiones y consultaba las indias tenidas por hechieras"3. El delito de adivinación por medio de las manos -quiromancia- se ve agravada por el de vanas observancias a los sueños. Tal como el fray dominico, también consultaba a hechiceros indígenas.

La calidad de mulato de Domingo Rojas tampoco parece ser el factor determinante. Juana de Castañeda, mulata, fue denunciada el 10 de diciembre de 1600 ante los veedores inquisitoriales en Chile y enviada a Lima para comparecer ante los tribunales por una serie de prácticas supersticiosas que incluían rezar a Santa Marta con dos velas de cera encendidas, por portar ara en una bolsita de tafetán colorado con el fin que "los hombres con quien tratase deshonestamente la quisiesen bien" $\mathrm{y}$ lograr su efectividad salmodiando un "ara, ara consagrada, en la mar fuiste hallada". También ésta había tratado con indios hechiceros, que adobaban sus botijas de chicha para que se vendiesen bien. Por estos delitos, abjurando de levi, recibió cien azotes y

${ }^{2}$ Medina, J. T.: "Historia del Tribunal del Santo Oficio de la Inquisición en Chile”. Fondo histórico y bibliográfico J. T. Medina, Santiago, 1952, p. 198.

${ }^{3}$ Ibíd, p. 220. La mujer tenía sobre sí otras acusaciones adicionales: bigamia, impedir matrimonios, hacer trabajar a los negros los días de fiesta.

${ }^{4}$ Ibíd, p. 280. 
destierro, además del infamante auto público.

Podríamos seguir enumerando casos similares pero creemos que la idea ha quedado expresada. En todos los casos derivados al Tribunal Inquisitorial de Lima, los reos no son indígenas y sus delitos van desde sencillas vanas observancias hasta la consulta de hechiceros, todas causas menos graves que el ejercicio del maleficio e incluso, de acuerdo al Inquisidor General Eimeric, sin pertinencia para la inquisición ${ }^{5}$.

Desconocemos las razones de por qué Domingo Rojas fue procesado en Talca. Quizás se deba a que tenía prontuario en la ciudad. Anteriormente Don Juan Joseph Bustamante había ordenado su encarcelamiento "porque andaba con una mujer al monte y era casada". Sabemos que logró escapar "trepando por los muros" y que al menos veinte reos más siguieron su notable ejemplo. En esta nueva ocasión, la administración ordenó a Theodoro de Fredes como juez del proceso para esclarecer las voces públicas que le vinculan al ejercicio de la hechicería. Rápidamente, Domingo Rojas es encarcelado y el juez se informa:

"por rrepetidos denuncios de pública voz y fama que Domingo Rojas mulato es hombre bagante osioso echisero que con sus echisos diabolicos tiene todo el lugar alborotado sin atender al cunplimiento anual de la yglesia ni oir misa sin temor a dios ni respeto a la rreal justisia"6.

Resulta interesante apreciar que, junto al delito central de hechicero se encuentra el de vagancia y ocio. Pero el eje del proceso lo constituye su ejercicio mágico y el uso de hechizos diabólicos -una redundancia- para trastornar la ciudad de Talca. Tanto su incumplimiento religioso así como su desidia frente a las autoridades son antecedentes que van perfilando al sujeto. El primer testigo llamado a declarar es el Capitán Don Pedro Lopes, de edad de 50 años, hombre que colaboró en apresar al mulato. Su declaración corrobora las presunciones del juez. Aseguro que "estando bibiendo en el lugar no lo a bisto confesar ni tanpoco oir misa", y lo que es peor, "sabe no bibe con la su mujer a tiempo de beinte años por aber cometido ynsestos con ermanas de la dicha su mujer"7. Añadiendo más antecedentes, el Capitán Pedro Lopes señala que Domingo Rojas intentó en varias ocasiones quitarle la vida a su mujer con un cuchillo y en otras ocasiones ahorcándola. Según la declaración de Lopes, el mulato se habría jactado de sus dotes mágicos, y "tenia alborotado barios lugares disiendo era brujo" y, en un escape de creatividad en el uso de sus facultades mágicas, "amenasando a muchas mujeres que si no dormian con el les abia de aser daño"s. Caminaba por Talca alardeando de sus facultades, diciendo que tenía "enfermó a fulano y fulana y que si le pagaban los sanaría".

\footnotetext{
${ }^{5}$ Eimeric, N. "El Manual de los Inquisidores (Directorium Inquisitorum)". Introducción y notas de Luis Sala-Molins. Muchnik Editores, Barcelona 1983. Nacido en 1320, Nicolau Eimerich escribió uno de los tratados más influyente en el procedimiento inquisitorial, con una importante proyección hacia los siglos posteriores. De acuerdo a sus escritos, "Los simples adivinos, o simples videntes: que únicamente practican la quiromancia (...) sus actividades no competen a la inquisición" (p. 78). Únicamente aquellos que cometen crímenes de latría (adoración) o dulía (veneración) demoníaca, o que mezclan elementos sacramentales con sus propios ritos, son considerados propiamente heréticos. Estos, en caso de no abjurar de sus delitos, "seran entregados, como herejes impenitentes, al brazo secular para sufrir el suplicio del fuego" (p. 79).

${ }^{6}$ A.N.Ch. Fondo Archivo Judicial de Talca, Legajo 233, Foja 1.

${ }^{7}$ A.N.CH. Fondo Archivo Judicial de Talca, Legajo 233, Foja 1r.

${ }^{8}$ A.N.CH. Fondo Archivo Judicial de Talca, Legajo 233, Foja 2.
} 
Un tópico bastante frecuente. Tanto en Hispanoamérica como en el contexto europeo propiamente tal, se establecía una consonancia natural entre la causa de un mal y su cura. La idea reposaba en un principio lógico: quien causaba un mal tenía los medios para poder revertir este proceso y, de igual manera, quien tenía aptitudes para sanar era un potencial maleficiador. Al final de su declaración, Pedro Lopes recuerda que el día que apresó a Domingo Rojas encontró entre las cosas de este "un atado" en el que se habrían encontrado soliman crudo y barios materiales anecsos a su arte diabolico" .

El segundo testigo, un hombre de treinta años llamado Francisco Arebalo, aseguró conocer al mulato por tiempo de veinte años, revelando que el mismo Domingo Rojas le ha dicho "que es brujo y que con la mujer que quiere dormir le ase malefisio y porque la sane se entregan"10. Confirma este pasaje asegurando haberlo visto tener "comunicasion ynlisita" con las mismas mujeres a las que originalmente había hecho daño. Al igual que el capitán Pedro Lopes, ratifica que el reo nunca iba a misa y, para mayor descaro, aprovechaba tales instancias para ir "con su manseba al monte con grandisimo escandalo". A las acusaciones hechas por el Capitán Lopes añade algunas de su cosecha personal.

"dise este declarante que teniendo una cuñada enferma la que el mismo le dijo estaba enferma de malefisio y que si le pagaban la sanaria y en efecto se determinaron a pagarle porque la sanase y estandola curando muchos dias no le aprobechaban sus medesinas disiendole la enferma que quando la alibiaba o la sanaba a esto le rrespondio el espresado mulato que no la sanaria menos que durmiese con $\mathrm{el}^{\prime \prime 11}$.

Tomando conocimiento de este ofrecimiento poco convencional que el mulato habría hecho a su cuñada, Francisco Arebalo declaró haberle dado de palos y amarrado, extrayendo de sus calzones "un atado de cabellos" que le parecieron similares a los de su cuñada. Ante las preguntas, Domingo Rojas habría contestado que eran de otra mujer llamada “Rosa Dias" y que el objetivo era encantarla para poder dormir con ella.

Retomando el análisis terminológico -sustento teórico de los procesos- podemos observar que esta última imputación, la del encantamiento, es la que lo sindica como hechicero propiamente tal y que lo aleja, en términos formales, de los cargos criminales de dañar y matar, propios de la brujería. Sin embargo, mucha de la terminología

\footnotetext{
${ }^{9}$ A.N.CH. Fondo Archivo Judicial de Talca, Legajo 233, Foja 2. También encontramos Solimán Crudo, en un caso de posesión demoníaca en Nueva España, también junto a otros dispositivos de innegable características negativas: lana, cabellos, agujas, alfileres. Bieñko de Peralta, Doris: “El cuerpo de la posesa. Discurso y práctica en torno a la posesión demoníaca en la Nueva España". En: "Revista destiempos (formato electrónico). Año 3, N¹4, México, 2008. Encontramos la voz "Solimán" relacionada con la Daphne laureola, una fanerógama perteneciente a la familia de las timeláceas. Todas las partes de la planta son venenosas y su savia fresca puede producir reacciones cutaneas alérgenas. A pesar de ser aparentemente un instrumento para la confección de venenos - y por extensión, de maleficios - parece haber tenido un cierto uso terapéutico. Bernardo de Vargas Machuca, en su libro Milicia y descripción de las Indias, escrito en 1599, menciona como componente básico del "botiquin del viajero" manzanilla, tabaco, azúcar, anime-copal, cardenillo y Solimán crudo. Flores Hernandez, B.: "Medicina de los conquistadores, en la Milicia Indiana de Bernardo de Vargas Machuca". En: "Boletín Mexicano de Historia y Filosofía de la Medicina". 2da época, volumen 6, N1, año 2003. Resulta enormemente curioso que el mismo término "Solimán" tenga aplicación en contexto de la minería colonial para referirse al Cloruro de Mercurio, como parte integrante del proceso de azogue en el tratamiento de la plata. Ver: Castillo Martos, M. “Bartolomé de Medina y el siglo XVI". Publicaciones de la Universidad de Cantabria, 2006, p. 210. En ambos casos, sin embargo, se está apelando a una sustancia con características de toxicidad.

${ }^{10}$ A.N.CH. Fondo Archivo Judicial de Talca, Legajo 233, Foja 2.

${ }^{11}$ A.N.CH. Fondo Archivo Judicial de Talca, Legajo 233, Foja 3.
} 
aplicada a los procesos tiene carácter adjetivante, siendo utilizada para reforzar una idea. De esta forma, al mulato Rojas se le acusa de realizar "hechizos diabólicos" cuando, para los teóricos e intelectuales analizados anteriormente, son diabólicos per se. En este caso, la apelación al término "diabólico" cumple el objetivo de remarcar el carácter negativo del ejercicio mágico. El mulato, de acuerdo a las testificaciones, se autocalifica brujo e incluso "el rrei de los brujos" de acuerdo a lo dicho por el tercer testigo Carlos Lopes. La justicia, sin embargo, tiene la precaución de iniciar el proceso por "echisero" y no por "brujo". Si fuese acusado por "brujería", estaría inmediatamente sujeto a la jurisdicción inquisitorial.

El ya mencionado Carlos Lopes -quien desconocemos si tiene algún parentesco con el Capitán Lopes- añade a las imputaciones el haberlo visto tratar "barias personas sacandoles del cuerpo barias porquerias asiendoles creer era malefisio"12. Dentro de las ideas que se manejan del maleficio, es especialmente recurrente la expulsión de "porquerías" o "alimañas", ya como síntoma del mal causado, ya como parte del proceso de sanación.

El Capitán Lopes deslizó una acusación de intento de homicidio en su primera declaración, la que fue ratificada por Bartolo Bidal, de cuarenta años, en su propia testificación. Junto con recordar la poca piedad de Rojas y su continua negativa a confesarse $u$ oír misa por más persuasiones que le haya hecho -aspecto que, junto a su fallida vida matrimonial son antecedentes de sospecha-. Pedro Lopes señaló la "amistad ynlisita" que mantenía el reo con las dos hermanas de su esposa, y cómo en una ocasión le quitó el cuchillo de las manos cuando se disponía a acuchillar a esta ${ }^{13}$.

Solo faltaba la testificación del propio Domingo Rojas. El veintiséis de septiembre de 1765 fue retirado de la cárcel y llamado para tomar su confesión de los crímenes imputados. Hizo su juramento "por Dios nuestro señor" realizando la protocolar señal de cruz en forma de derecho. Señaló estar casado con Pasquala Riberos y que el oficio al que se dedica es el de zapatero. Al preguntársele de qué modo hacía "las brujerías"14, Domingo Rojas contestó que "quando bebía un trago de vino les desia a la jente cuidado conmigo que traigo la mano cargada y soy brujo"15. Así, de forma tajante, llevó el plano factual del ejercicio de la hechicería a lo que estrictamente podríamos reconocer como un discurso. El mulato decía que era brujo, como vimos, para lograr fines concretos y, de acuerdo a las acusaciones imputadas, este uso intimidatorio del término "brujo" parecía ser bastante efectivo.

A la pregunta de si había extorsionado a la cuñada de Francisco Arebalo -llamada Juana Romero- él "responde que no se aquerda" y que toda su participación se redujo a darle "una bebida que (...) la yso bomitar un animalillo como un ylo colorado"16, otro tópico de larga data que veremos presente en algunos de los procesos analizados.

\footnotetext{
${ }^{12}$ A.N.CH. Fondo Archivo Judicial de Talca, Legajo 233, Foja 3.

${ }^{13}$ A.N.CH. Fondo Archivo Judicial de Talca, Legajo 233, Foja 4.

${ }^{14}$ Acá el término Brujerías es utilizado sin rigor, con el fin de designar actividades maléficas y dañinas. Está desprovista de la carga teórica que, tal como señalamos, eran manejados por jueces más instruidos en estas materias.

${ }^{15}$ A.N.CH. Fondo Archivo Judicial de Talca, Legajo 233, Foja 5.

${ }^{16}$ A.N.CH. Fondo Archivo Judicial de Talca, Legajo 233, Foja 5.
} 
Sobre el atado de cabello encontrado, clara señal del uso de encantamiento, corroboró lo dicho por los testigos confesando que "eran cabellos de una niña llamada Rosa Dias y Bartolo Bustamente padrastro de dicha niña se los dio para que ysiese un muñeco y lo quisiese dicha niña" ${ }^{17}$. El atado de porquerías que le encontró el Capitán Lopes cuando lo apresaron fue una pregunta insalvable, dadas las enormes susceptibilidades que, como veremos, dichas bolsas o atados provocan. Sin poder negarlo, el mulato contestó que dicho etado eran "contras para defenderse de los brujos".

Si niega haber realizado las prácticas mágicas que se le imputan, no ocurre lo mismo con las otras acusaciones. Preguntado sobre su amancebamiento confiesa que hace doce años no convive con su esposa y cerca de un año que lleva amancebado con otra mujer. Asimismo, reconoce haber tenido "amistad ynlisita" con las dos hermanas de su esposa. Sobre los intentos de homicidio con cuchillo hechos contra su esposa, confiesa -con una honestidad sorprendente- que "degollarla no quiso, sino darle de puñaladas" ${ }^{\prime 18}$. La justicia le da dos días para apelar y, tras no presentarse, es encarcelado.

El caso de Domingo Rojas es particularmente importante por tres aspectos: en primer lugar, nos permite ver el uso de terminología específica aplicada tanto a los jueces como al propio imputado. Echisos, Bruxerias y maleficios, son indistintamente utilizados para apelar a un mismo tipo de práctica, aun cuando el núcleo intelectual de la Iglesia teorizó durante siglos sobre los alcances y especificidad de estos delitos de heterodoxia. En segundo lugar, nos permite tomar conciencia de cómo los "echisos demoníacos" y su fama de "rrei de los brujos" producen un efecto público real en Talca, logrando desde un modesto alarde de fuerzas con sus pares, hasta extorsiones con fines sexuales en una espléndida prueba de cómo la población es sensible y receptiva a estas prácticas, mostrándonos cómo, junto a un componente esencialmente discursivo -e instrumental- convive una praxis real con efectos concretos en la sociedad. Resulta también curioso el contraste entre su abierta aceptación de las imputaciones de otros crímenes -amancebamiento e intento de homicidio- y su negativa a aceptar el ejercicio mágico que se le hace cargo. Aunque la competencia de los tribunales ordinarios se expresaba en el ámbito criminal del delito, es visible el impacto que las imputaciones de heterodoxia tuvieron entre los testigos y los jueces. Inscrito en un proceso de mayor envergadura, la causa de Domingo Rojas nos habla de un lenguaje común, un conjunto de códigos que la sociedad colonial maneja, comprende y que permite el diálogo entre testigos, reos y jueces a partir de los mismos signos.

\footnotetext{
${ }^{17}$ A.N.CH. Fondo Archivo Judicial de Talca, Legajo 233, Foja 5. La declaración de Domingo Rojas pone en manifiesto una práctica ampliamente documentada en el contexto colonial: la recurrente presencia de españoles acudiendo a las castas y al mundo indígena para solucionar sus conflictos por vías mágicas. Las disposiciones del Sínodo de Santiago de 1626 indican, en su constitución tercera, la pena de excomunión a todos aquellos que consultan a indios para saber "cosas que naturalmente no se pueden saber" y "alcancen lo que ilícitamente desean". Cavada Oviedo, C. "Sínodo Diocesano de Santiago de Chile. Celebrado en 1626 por el ilustrísimo señor Francisco Gonzalez de Salcedo. Transcripciòn, introducción y notas de Fr. Carlos Oviedo Cavada". En: "Revista Historia", No3, Pontificia Universidad Católica de Chile, 1964. En el ya mencionado trabajo de Medina, figura también una mulata de nombre María Martínez, deportada a Lima por sus crímenes de heterodoxia, entre los que se señala el adivinar si tal o cual hombre se casaría con tal o cual mujer. Era conocida por brindar este tipo de servicios.

${ }^{18}$ A.N.CH. Fondo Archivo Judicial de Talca, Legajo 233, Foja 6.
} 
TRANSCRIPCIÓN:

“PROCESO A DOMINGO ROJAS, MULATO, POR HECHICERO Y VAGO. 1765"

\section{Foja 1}

\section{"Causa criminal contra Domingo Rojas}

Por quanto estoi ynformado por rrepetidos denuncios de pública ---fama que Domingo Rojas mulato es hombre bagante osioso echisero que con sus echisos diabolicos tiene todo el lugar alborotado sin atender al cunplimiento anual de la yglesia ni oir misa sin temor a dios ni respeto a la rreal justisia y para que dicho domingo rojas sea correjido en las operaciones dandole la pena correspondiente a los delitos en cuya birtud debi de mandar y mande que de ofisio de la Real Justisia se le siga al dicho reo la sumaria aberiguasion de su modo de bida y perasiones exsaminando los testigos que supiesen de ellas al pie de este auto el que sirbe de cabesa de proseso y para que con este que asi lo mande lo firme en este asiento de salinas doctrina de vichuquen jurisdision del partido de Maule en beinte y quatro días del mes de septiembre de mil setesientos sesenta y sinco años yo Don Theodoro de fredes jues de comision en dicha doctrina = actuando con testigos por falta de escrribano y de ello doi fe $=$ Testigo Visente Flores

Por mi ante mi Theodoro Fredes y luego yncontinenti en dicho dia mes y año y dicho jues para la sumaria aberiguasion de las malas

\section{Foja 1 (anverso)}

operasiones y modo de bida en que se exersita Domingo Rozas segun lo tengo mandado por auto por mi probeido yse comparaser ante mi en mi jusgado al capitan de actual exersisio Don Pedro Lopes de quien rresibí juramento quien lo yso por Dios nuestro señor y una señal de crus en la forma de derecho so cargo del qual prometio desir berdad en lo que supiere y le fuere preguntado y siendole exsaminado al tenor del auto que esta por cabesa de proseso dijo que conose a Domingo Rojas reo contenido en dicha sumaria a tiempo de quarenta años y que sabe esta preso por barias maldades que a executado y estaba executando antes de estar preso y disiendole pues las sabe las esprese en el modo que las sabe, y dixo que lo primero y prinsipal que estando bibiendo en el lugar no lo a bisto confesar ni tanpoco oir misa tanbien dise este declarante que sabe no bibe con la mujer a tiempo de beinte años por aber cometido ynsestos con ermanas de la dicha su mujer yten dise que en barias ocasiones a yntentado el quitarle la bida a dicha su mujer con el cuchillo y en otra ocasión la tubo casi aorcada yten dise este declarante que sabe y le consta que dicho reo fue causado y rremitido a la carsel de Talca por don Juan Joseph Bustamente siendo jues de esta dicha doctrina cuya causa se allare en el archibo de la dicha billa y asi mesmo sabe 


\section{Foja 2}

yso fuga de dicha carsel escalandola con otros mas de los presos, yten dise este declarante que sabe que de lugar en lugar pasandose a un partido a otro sin temor a Dios ni rrespeto a la rreal justisia, yten dise este declarante que sabe y consta que dicho rreo tenia alborotado barios lugares disiendo era brujo, amenasando a muchas mujeres que si no dormian con el les abia de aser daño = y en confirmasion de ello desia que teni(a) enfermo a fulano y fulana y que si le pagaban los sanaria y que asi mesmo le ha bisto que a sanado a muchos mas dise este declarante que el dia que lo cojio le allo hun atado que en el atado segun se a manifestado se alla en dicho atado soliman crudo y barios materiales anecsos a su arte diabolico yten dise este declarante que quando lo cojio preguntandole que si era sierto que tenia enferma a Juana Romero por lo mesmo que el desia respondio dicho rreo que la daria sana dentro de ocho días = y que es la berdad lo que lleba dicho y declarado so cargo del juramento que fecho tiene en el que se le afirmo y rratifico y siendole leida su declarasion dijo ser sierta y que es de edad de sinquenta años y que no le tocan las jenerales de la lei y firmo su declarasion junramente conmigo y testigos con quienes actuo por falta de escrribanos y de ello doi fe $====$

\section{Foja 2 (anverso)}

Pedro Lopez, tto Vizente florez, tto casimiro cuebas

Por mi ante mi

Theodoro frdes

en dicho dia mes y año yo dicho Jues para en presecusion de dicha sumaria yse conpareser ante mi y en mi jusgado a Francisco Arebalo de quien rresebío juramento quien lo yso por Dios Nuestro Señor y una señal de crus conforme a derecho so cargo del qual prometio desir berdad en lo que supiere y le fuere preguntado y siendole exsaminado al tenor del auto que esta por cabesa de proceso dijo que conose a domingo rojas mulatos reo contenido en dicha sumaria a tienpo de biente años y que sabe que esta preso por barias maldades que a executado y disiendole pues lo sabe las esprese en el modo que las sabe y dijo qe el mesmo Domingo Rojas le a dicho en muchas ocasiones que es brujo y que con la mujer que quiere dormir le ase malefisio y porque la sane se entregan a el y en confirmasion de lo dicho lo beia tener comunicasion ynlisita con algunas mujeres las mesmas a quien les a echo daño, Yten dise este declarante

\section{Foja 3}

que sabe que nunca se confiesa ni oye misa antes si en barias ocasiones lo conbidaban este dicho declarante y otros para que fuese a confesarse y a oir misa y nunca quiso mas dise este declarante que sabe y le consta que andaba con su manseba al monte con grandisimo escandalo mas dise este declarante que teniendo una cuñada enferma la que el mismo le dijo estaba enferma de malefisio y que si le pagaban la sanaria y 
en efecto se determinaron a pagarle porque la sanase y estandola curando muchos dias no le aprobechaban sus medesinas disiendole la enferma que quando la alibiaba o la sanaba a esto le rrespondio el espresado mulato que no la sanaria a menos que durmiese con el y entonses le dio de palos y lo amarro y del forro de los calsones le saco un atado de cabellos los que cotejados con los de la enferma paresen ser de la dicha y preguntandole para que traia ya aquel cabello rrespondio que no era de ella sino de otra y preguntandole por el dicho declarante para que los tenia rrespondio que eran para encantar a Rosa Dias para poder dormir con ella, Yten dise este declarante que sabe y le consta que escalo la carsel de Talca y que es la berdad todo lo que lleba dicho y declarado so cargo del juramento que fecho tiene en el que se afirmo y ratifico y siendole leida su declarasion dijo ser sierta y que es de edad de treinta años y no le tocan las jenerales de la lei = no firmó su declarasion porque dijo no saber y a su

\section{Foja 3 (anverso)}

rruego lo firmo uno de los testigos con quienes acuto por falta de escribano y de ello doi fe $=$ a rruego del declarante y por testigo Vizente Flores. Testgo Casimiro Cuebas. Por mi ante mi Theodoro Fredes

y luego yncontinenti en dicho dia mes y año y dicho jues para la sumaria aberiguasion de las malas operasiones y modo de bida en que se ocupa domingo Rojas mulato segun lo tengo mandado por auto yse comparaser ante mi y en mi juzgado al cabo de esquadra de actual ejersisio Carlos Lopes de quien rresebi juramento quien lo yso por Dios nuestro señor y una señal de crus conforme a derecho so cargo del qual prometio desir berdad en lo que supiere y le fuere preguntado y siendole exsaminado al tenor del auto que esta por cabesa de proceso dijo que conose a Domingo rojas reo contenido en dicha sumaria a tienpo de dies y seis años y que sabe esta preso por barias maldades que a executado sin temor a Dios ni rrespeto a la rreal justisia y disiendole puestos sabe los esprese en el modo los sabe y dijo primeramente sabe no se confiesa ni oye misa mas dise este declarante que sabe que andaba con su manseba al monto con grandisimo escandalo mas dise que el mismo mulato le comunicaba era brujo y que le asia malefisio a quien se le antojaba y que era el rrei de los brujos y que a la persona a quien le le asia daño nadie le abia de sanar sino el y asi se a bisto con barias personas sacandoles del cuerpo barias porquerias asiendoles creer era malefisio y que al fin de todo desia el les abia echo aquel daño y en par-

\section{Foja 4}

ticular a las mujeres por el ynteres de dormir con ellas y que es la berdad lo que lleba dicho y declarado de publica bos y forma so cargo del juramento que fecho tiene en el que se afirmo y rratifico y siendole leida su declarasion dijo ser sierta y que es de edad de treinta años y no le tocan las jenerales de la lei y no firmo su declarasion porque dixo no saber y a su rruego la firmo uno de los testigos con quienes actuo por falta deescrribano y de ello doi fe $=$ a rruego del decalrante y por testigo Vizente flores Testigo casimiro cuebas. 
Y luego yncontinenti el dicho dia mes y año yo dcho jues en prosecusion de dha sumaria hise comparser ante $\mathrm{m}$ en mi jusgado a bartolo bidal de quien recebi juramento quien lo yso por Dios Nuestro señor y una senal de cruz en forma de derecho so cargo del qual prometio desir berdad en todo que supiere y le fuere preguntado y siendole exsaminado al tenor del auto qeu esta por cabesa de proseso dijo que conose a Domingo Rojas reo contenido en dha sumaria a tienpo de treinta años y que sabe esta preso por barios delitos que sabe a executado y disendole pues lo sabe lo esprese y dijo que sabe y le consta que no se a confesado nunca ni a oido misa por mas persuasiones que le haya echo, Yten dise este declarante que habra tienpo de onse años que no ase bida con la mujer $=$ y preguntandole a este declarante por que no asia bida con la mujer dicho mulato rresponde que por que tubo

\section{Foja 4 (anverso)}

amistad ynlisita con dos ermanas de la dicha su mujer con las quales andubo al monte mas dise este declarante que en barias ocasiones quiso degollar su mujer y en una ocasion le quito el cuchillo al executar una y muchas puñaladas que le tiraba a su mujer, Yten dise este declarante que a oido desir que es brujo que handa hasiendo malefisio a barias personas, yten dise este declarante que sabe fue causado por Don Juan Joseph Bustamente siendo Jues de esta doctrina y rremitio a la carsel de san Agustin de Talca de donde yso fuga escalando la carsel con otros presos mas esto es lo que sabe este declarante y esto dise lo sabe por aberlo bisto so cargo del juramento que fecho tiene en el que se afirmo y rratifico y siendole leida su declarasion dijo ser sierta y que es de edad de quarenta años y no le tocan las jenerales de la lei y no firmo su declarasion porque dijo no saber y a su rruego la firmo uno de los testigos con quienes actuo por falta de escribano y de ello doi $\mathrm{fe}=$ a rruego de este declarante $\mathrm{y}$ por testigo Visente Flores

Autos y vistos tomosele su confesion al rreo contenido en esta causa, tto antonio [fre] des

Asi loprobe mande y firme yo Don thedoro fredes de comision en dha doctrina en beinte y seis dias del mes de septienbre de mil setesientos sesenta y sinco años en presencia

\section{Foja 5 (confesion del reo)}

De testigos con quienes actuo por falta de escribano de que doy fee $=$ tto casimiro cuebas tto Antonio fredes

En el asiento de las salinas doctrina de vichuquen jurisdision del partido de Male en beinti seis dias del mes de septiembre de mil setesientos sesenta y sinco años yo Don theodoro fredes jues de comision en dicha doctrina para efecto de tomarle su confesion a este hombre preso en mi justago le yse conpareser ante mi y del rresibi juramento quien lo yso por Dios nuestro señor y una señal de crus en forma de dho so cargo del qual prometio desir berdad en lo que supiere y le fuere preguntado y 
siendol exsaminado preguntandole como se llama que edad tiene de donde es natural que estado tiene y que ejersisio tiene para mantenerse y si sabe la causa de su prision. Dijo llamarse Domingo Rojas - que es de edad de quarenta años mas o menos que es natural de esta doctrina de Vichuquen que es casado con Pasquala Riberos que el ofisio que tiene para mantenerse es de sapatero esto rresponde y que sabe que esta preso por brujo a lo que se pregunta en que modo asia estas brujerias responde que quando bebia un trago de vino les desia a la jente cuydado conmigo que traigo la mano cargada y soy brujo, ytten le pregunte que como habia sanado a las personas que habia curado rresponde que con ------ que le dan sus amigos, ytten le pregunte si era sierto qle abia dicho a Juana Romero que si dormia con el la sanaria responde que no se aquerda si lo dijo mas le pregunte que como la abia curado y rresponde que con una bebida que le dio la yso bomitar un animalillo como un ylo colorado, ytten le pregunte que a que fin tenia un atado de cabellos en la pretina de los calsones los mesmos que le quito Francisco Arebalo confiesa que eran cabellos de una niña llamada Rosa Dias y Bartolo Bustamente padrastro de dicha niña se los dio para que ysiese un muñeco y lo quisiese dicha niña, ytten le pregunte que para que tenia el atado de porquerias que le quito el capitan lopes quando lo despache a cojer confiesa que eran contras para defenderse de los brujos, ytten le pregunte quantros años a que no cunple con el presepto anual de la yglesia confiesa que ase nuebe años a que no confiesa ni comulga, ytten le pregunte que quantos años ase que andaba con su manseba al monte confiesa que ase un año mas le pregunte que tienpo ase que no bibe con su mujer confiesa

\section{Foja 6}

que a tienpo de dose años, ytten le pregunte por que no ase vida con la mujer confiesa que por aber tenido amistad ynlisita con dos ermanas de la dicha su mujer mas le pregunte si era sierto quiso degollar a su mujer confiesa que degollarla no quiso sino darle de puñaladas, ytten le pregunte en que modo yso fuga de la carsel de San Agustin de Talca confiesa que otros presos escalaron la carsel abriendo un portillo y lo sacaron y salio con beinte tantos mas, yten, lre pregunte por que lo causo Don Juan Joseph Bustamente confiesa que porque andaba con una mujer al monte y era casada = esto es lo que confiesa el rreo contenido en estos autos y que esta berdad todo lo que lleba confesado so cargo del juramento que fecho tiene y siendole leida su declarasion o digo su confesion dijo ser la mesma que fecha tiene y no la firmo porque dijo no saber y a su rruego firmo uno de los testigos con quienes actuo por falta de escribano y de ello doy fe $=$ y por testigo. Antonio Fredes, casimiro cuebas. Por mi ante mi theodoro fredes

Auto de culpa y cargo $=$

Yo don theodoro fredes jues de comision en dha doctrina abiendo visto los autos y confesion del reo Domingo rojas reo contenido en esta 


\section{Foja 6R}

Sumaria y visto los meritos de ella le devia de aser esta culpa y cargo de --- delitos por el que se la ha trasladado para que dentro de segduno dia diga y alege lo que -----conbenga con apersebimiento que no lo asiendo entre el termino rreferido se rresibira la causa a preba co termino de seis dias con todos cargos y se rratificara los testigos de la sumaria entro de dcho termino y se le ara saber a dho rreo este auto para que conste $=$ fredes

En dho dia mes y año yo dho jues y en presensia de testigos notifique este saber el auto de la buelta a Domingo Rojas reo contenido en esta cauesa de que doy fee $=$ ttgo Antonio fredes, tto casimiro cuebas. Por mi ante mi theodoro fredes

Cunplidos los dos dias quese mandaron por el auto de culpa y cargo responde que no tiene que rsponder ni como eso rresponde el rreo contenido en estos autos por lo que mando se rremita a la carsel de san agustin de talca y se le de parte a m correjidor $=$ fredes 